Review Article

\title{
A succinct medical safety: periodic safety update reports
}

\author{
Arun Chander Yadav Krishnamurthy ${ }^{1}$, Jayasudha Dhanasekaran², Anusha Natarajan ${ }^{1 *}$
}

${ }^{1}$ Department of Pharmacology, JIPMER, Pondicherry, India

${ }^{2}$ Department of Medicine, Madras Medical College, Chennai, Tamil Nadu, India

Received: 02 May 2017 Accepted: 27 May 2017

*Correspondence to:

Dr. Anusha Natarajan, Email: anushanatarajan29@ gmail.com

Copyright: (C) the author(s), publisher and licensee Medip Academy. This is an openaccess article distributed under the terms of the Creative Commons Attribution NonCommercial License, which permits unrestricted noncommercial use, distribution, and reproduction in any medium, provided the original work is properly cited.

\begin{abstract}
In the rapidly developing era of advanced of medical sciences, pharmacovigilance plays an important role to put necessary brakes and help the medical fraternity to prescribe in a safe manner. Unanimously PSUR contributes in an essential way to regulate the drug marketing agencies to make sure that biological products which are marketed do not harm the general population by its adverse drug reactions. As we all know that the regulatory agencies like EMA, US FDA, CDSCO etc. are very stringent in approving the drugs, they have framed several rules and imposed strict timelines for reporting the necessary documents pertaining to drugs. Inevitably several new drugs like immunomodulators, anticancer drugs are on the raise which further adds a huge responsibility on the regulatory agencies regarding the risk and benefits of such biological products. Thus, the regulatory agencies have added several new implementation and amendments in the existing rules for the marketing of new drugs as well as already prevailing drugs. Hence, it is of paramount importance for the drug companies to follow the guidelines and abide by the rules of regulatory agencies for the benefit of mankind. However, several factors can impede the process of PSUR like improper data retrieval, inadequate training of resource personnel concerned with the development of PSUR. To overcome such difficulties, the field of advanced technology extended its arms for the regulatory authorities to implement electronic documentation and databases for the development of PSURs. In spite of all these efforts several challenges are to be met in the future in the field of pharmacovigilance. In this review several aspects of PSUR in different countries, necessary processes and format in which it needs to be submitted, pitfalls and ways to overcome such situations have been discussed in brief. Therefore, it is the collective responsibility of both Regulatory agencies and the drug companies to ensure a good quality PSUR is produced with its benefits outweighing the risk of the drug for the suffering human population.
\end{abstract}

Keywords: Periodic safety update report, Periodic benefit-risk evaluation report, Pharmacovigilance

\section{INTRODUCTION}

"The periodic safety update report (PSUR) is a document that allows a periodic, comprehensive assessment of the worldwide safety data of a marketed drug or a biological product". Council for International Organizations of Medical Sciences(CIOMS) Working Group II report introduced this concept in the year 1992 and later CIOMS II formed the basis for ICH(International Conference on Harmonization) In November 1996, the ICH endorsed the ICH E2C Periodic Safety Update Report Guideline (E2C guideline), which established the PSUR as a harmonized format for post-market periodic safety reporting for approved drugs and biologic products, and described the format, content, and timing of PSUR submissions. FDA adopted that guideline and, in May 1997, published it as FDA guidance for industry E2C Clinical Safety Data Management: Periodic Safety Update Reports for Marketed Drugs (ICH E2C guidance).

In February 2003, ICH endorsed and made final an addendum that further clarified some aspects of the $\mathrm{ICH}$ E2C guidance. In February 2004, FDA published the addendum as FDA guidance for industry Addendum to E2C Clinical Safety Data Management: Periodic Safety Update Reports for Marketed Drugs (addendum to the 
E2C guidance). On April 11, 2012, FDA announced the availability of a draft guidance for industry entitled E2C (R2) Periodic Benefit-Risk Evaluation Report (PBRER), which describes the format, content, and timing of the PBRER as presented in the ICH step 2 guideline. ICH subsequently endorsed a final version of that guideline on November 15, 2012, and published the ICH harmonized tripartite guideline Periodic Benefit-Risk Evaluation Report (PBRER) E2C (R2) (ICH E2C (R2) step 4 guideline). This new ICH guideline updates and combined with the E2C guideline and an addendum to the E2C guideline in particular, it replaces the PSUR with the PBRER for post-market periodic safety reporting, and describes the recommended format, content, and timing of PBRER submissions. Like its predecessor, the PSUR, the harmonized PBRER is intended to promote a consistent approach to periodic post-market safety reporting among the $\mathrm{ICH}$ regions and to enhance efficiency by reducing the number of reports generated for submission to the regulatory authorities. ${ }^{1,2}$

\section{PSUR/PBRER, DSUR AND ODDAR}

\section{PSUR}

It is a document containing comprehensive overall safety information of a marketed drug or biological product which is submitted by MAH to the regulatory authorities periodically as recommended by ICH E2C guidelines.

\section{PBRER}

PSUR term got changed to PBRER according to ICH E2C (R2) step 4 guideline and focus is more on critical analysis of new or emerging information on the risks of the medicinal product, and on its benefit in approved indications, to enable an appraisal of the product's overall benefit-risk profile.

\section{DSUR}

Development Safety Update Report is a document containing a comprehensive annual review and evaluation of safety information for drugs under development (including the drugs marketed which are to be further studied). It is done annually in contrast with PSUR/PBRER which is done in a periodical manner as 6 monthly or quarterly in a year depending on the different regulatory requirements across different countries.

\section{ODDAR}

Orphan Drug Designation Annual Report is a document that includes short account of the progress of drug development including a review of preclinical and clinical studies initiated, ongoing, and completed and a short summary of the status or results of such studies and also the description of the investigational plan for the coming year, as well as any anticipated difficulties in development, testing, and marketing; and also any changes that may affect the orphan-drug status of the product. The submission period is within 14 months after the date on which a drug was designated as an orphan drug and annually thereafter until marketing approval is obtained. ${ }^{3}$

\section{International birth date (IBD)}

Date of the first marketing authorization for necessary granted in any country of the world.

\section{Data lock point $(D L P)$}

Cut-off date to be included in the PSUR, it may be set according to the international birth date (IBD) from the medicinal product. After obtaining marketing authorization for a medicinal product, the MAH is requested to inform the Agency of their choice of birth date and of the chosen first data lock point ( $1^{\text {st }}$ DLP).

\section{Company core data sheet (CCDS)}

A document prepared by Marketing Authorization Holder (MAH) containing material relating to indication, dosing, pharmacology and additional information concerning the product as well as to safety information.

\section{Company core safety information (CCSI)}

All relevant safety information contained in the CCDS prepared by the MAH and which the MAH requires to be listed in all countries where the company markets the drug, except as soon as the local regulatory authority specifically needs a modification. This is the reference information with which listed and unlisted are determined for the goal of periodic reporting for marketed products, but not by way of expected and unexpected are determined for expedited confirming.

\section{Bridging report}

Concise document that integrates two greater PSUR, format identical on the usual PSUR, content should consist of summary highlights and overview of info. Under ICH E2C Regulators who do not will require receive 6 month report, bridging report can be taken.

\section{Addendum report}

An update to probably the most recently completed PSUR, typically requested from your regulatory authorities outside distinct. IBD cycle and also for time lapse cases beyond the DLP (i.e. 3 months for a 6 month report and 6 months for a single year report, to be submitted as addendum in usual PSUR format).

Adverse drug reaction listed associated with CCSI.

Adverse drug reaction not placed in the current CCSI. ${ }^{1,3}$ 


\section{WHY PSUR?}

A new medicinal product is submitted for marketing approval by testing its effectiveness and safety only in few thousand patients. Limited associated with patients in clinical trials, the connected with long term treatment experience and the limitation of concomitant therapies make the detection of rare adverse drug reactions quite difficult. Therefore in order to build a comprehensive picture on clinical safety profile, new medicinal products should be closely monitored in first few involving marketing.

\section{Regulations in PSUR}

\section{In India}

As per the requirements of Schedule "Y" of the Drugs and Cosmetic Rules, PSUR of new drugs are required to be submitted to the office of DCG (I).

- $\quad$ Every 6 months for the 1 st 2 years

- For the next 2 years PSUR shall be submitted annually.

- $\quad$ PSURs due for a period must be submitted within 30 calendar days of the last day of the reporting period.

The PSURs should be structured as per clause (v) of Schedule "Y" which is under and the report should be India specific:

- A title page stating: PSUR for the product, applicant's name, period covered by the report, date of approval of new drug, approved indication, date of marketing of new drug and date of reporting.

- Introduction

- Current worldwide market authorization status

- Update of actions taken for safety reasons

- Changes to reference safety information

- Estimated patient exposure

- Presentation of individual case histories

- Studies

- Other information

- Overall safety evaluation

- Conclusion

- Appendix providing material relating to indications, dosing, pharmacology and other related information. ${ }^{4}$

In USA

US FDA requires 3 months once the actual first 3 years, then annual reports needs pertaining to being submitted.

\section{In European Union}

EMA (European Medicines Agency) requires reports initially every several weeks for the first 2 years, then annually for the subsequent 3 years which usually every 5 years, at time of renewal registration.

\section{In Japan}

Secretary of state for health requires reporting every 6 months for the first 3 years and annually thereafter. ${ }^{2,3}$

\section{GENERAL PRINCIPLES IN PBRER}

\section{Single PBRER for a productive substance}

The PBRER should showcase all approved indications, dosage forms, and regimens for that active substance, with merely one DLP. In most circumstances, it will appropriate to give data by indication, dosage form, dosing regimen, or population (e.g., children or. adults) within the relevant areas of the PBRER. In exceptional cases, submission of separate PBRERs might be appropriate, for example, an engaged substance implemented in two formulations for systemic and topical administration in entirely different indications. During these cases, the regulatory authorities should be notified in addition agreement obtained, preferably is now the top approval.

\section{PBRERs for fixed dose combination product}

For mixtures of substances also marketed individually, information for your fixed combination may be reported in a choice of a separate PBRER or included separate presentations your market report for starters of the litigant substances, with regards to the circumstances. Listing related PBRERs is considered important.

\section{Products manufactured and/or marketed by many company}

Each MAH is in control of submitting PBRERs for its very own products in case companies take part contractual relationships (e.g., licensor-licensee), respective responsibilities for preparation and submission of the PBRER towards regulatory authorities should be clearly laid out in the written agreement. Predicaments when data received out of a partner company/ companies might contribute meaningfully to the safety, benefit, and/or benefit-risk analyses and influence the reporting company's product information; these data should be included and discussed their PBRER. ${ }^{5}$

\section{PBRER process}

The main objective of a PBRER is to present a comprehensive, concise and critical research into the riskbenefit balance of this medicinal product considering new or emerging information in the context of cumulative information on risks and benefits. The PBRER is therefore a tool for post-authorization evaluation at defined time points in the lifecycle of a service or product. The analysis of the risk-benefit balance should 
incorporate an evaluation of this safety, efficacy and effectiveness information crucial available with reasonable and appropriate effort, during the reporting interval for the medicinal product in the context of the amount known previously. The integrated benefit-risk evaluation should be performed for all authorized indications and should incorporate the evaluation of risks in a variety of use of the medicinal product (including use in unauthorized indications).

The evaluation should involve:

1. Critically examining the information offers emerged during the reporting interval to discover whether it has produced new signals, contributed to the identification of recent potential or identified risks or led to knowledge of previously identified risks.

2. Critically summarizing relevant new safety, efficacy and effectiveness information that will have an impact relating to the risk-benefit balance for the medicinal product.

3. Conducting a built-in benefit-risk analysis regarding authorized indications by the cumulative information available since the International birth date (IBD).

4. Summarizing any risk minimization actions that may are taken or implemented during the reporting interval, as well as risk minimization actions that are planned to be implemented.

5. Outlining plans for signal or risk evaluations including timelines and/or proposals for additional Pharmacovigilance activities.

Eclipses the others PBRER process:

- Intake of ADR information

- Case processing

- Data retrieval

- Data analysis

- Medical review and risk assessment.

Adverse reaction data from the following sources are potentially available to the MAH and so would be likely to be included a PBRER if they exist. The reaction terms used in PBRER will be generally derived from MedDRA (Medical Dictionary for Regulatory Activities). The source for PBRER can be obtained as follows:

- Direct reports to the MAH: Internal revenue service reports regarding example spontaneously notified by Clinical professionals, from MAH-sponsored studies, from named patient or compassionate use schemes and from patients or potential clients.

- Adverse reaction reports from literature.

- Adverse reaction reports received from regulatory authorities' database. This may include nonmedically confirmed patient or consumer answers.

- Reports using sources with regard to those using their company companies, from registries, from poison control centers or epidemiological data banks. ${ }^{5,6}$

\section{Format of PBRER}

Electronic Periodic Benefit Risk Evaluation Report format is as follows:

1. Part I: Title page including signature

2. Part II: Executive Summary

3. Part III: Table of Contents

1. Introduction

2. Worldwide marketing authorization status

3. Actions taken in the reporting interval for safety reasons

4. Changes to reference safety information

5. Estimated exposure and use patterns

- Cumulative subject exposure in clinical trials

- Cumulative and interval patient exposure from marketing experience

6. Data in summary tabulations

- Reference information

- Cumulative summary tabulations of serious adverse events from clinical trials

- Cumulative and interval summary tabulations from post-marketing data sources

7. Summaries of significant findings from clinical trials during the reporting interval

- Completed clinical trials

- On-going clinical trials

- Long-term follow-up

- Other therapeutic use of medicinal product

- New safety data related to fixed combination therapies

8. Findings from non-interventional studies

9. Information from other clinical trials and sources

10. Non-clinical Data

11. Literature

12. Other periodic reports

13. Lack of efficacy in controlled clinical trials

14. Late-breaking information

15. Overview of signals: new, on-going or closed

16. Signal and risk evaluation

- Summaries of safety concerns

- Signal evaluation

- Evaluation of risks and new information

- Characterization of risks

- Effectiveness of risk minimization (if applicable)

17. Benefit evaluation

- Important baseline efficacy and effectiveness information 
- Newly identified information on efficacy and effectiveness

- Characterization of benefits

18. Integrated benefit-risk analysis for authorized indications

- Benefit-risk context- Medical need and important alternatives

- Benefit-risk analysis evaluation

19. Conclusions and actions

20. Appendices to the PBRER

- Company Core Data sheet

- Marketing authorization status

- Line listing of case report

- Summary tabulation of events. ${ }^{7}$

\section{PBRER safety concerns}

Even though PBRER has been recently evolved as a significant safety tool in post marketing surveillance, there are multiple factors including product characteristics, regulatory approval status and timing of approval that could potentially change the outcome of PBRER quotes. It should be noted that PBRERs are not meant to be a 'signal detection tool', but rather to be a tool to periodically assess the overall safety profile with a medicinal product. The new format of PBRER includes discussion on both benefits and risks, with an importance on Benefit/Risk assessments and ICH have also proposed a modular design to facilitate differences in international reporting requirements and the harmonization with preauthorization safety reports. In a study, cross sectional analysis was performed of follow-up requirements of PSURs submitted for centrally approved biopharmaceuticals in the Western European (from 1 July 2008 till 30 June 2010). With respect to this study they found that regulatory actions occurred a bit more often after assessment of PSURs of the ATC class of 'immunomodulators and antineoplastic agents' are cheaper and also being reported that a popular of post approval safety warnings issued for pharmaceuticals are associated to their immunomodulatory effects. In accessory for this PSURs for that products approved for extended than 10 years, the frequency of Summary Product Characteristics (SPC) changes was significantly lower than compared to younger products. Also a true problem when assessing the contribution of PSURs in apparently management of bio pharmaceuticals is achievable of a control group. ${ }^{8}$

\section{Pitfalls of the PBRER}

\section{Intake of ADR information}

As mentioned previously earlier there are incredibly many sources can contribute to ADR information in PBRER but
Individual case safety report (ICSR) is the security unit of the PBRER. So organization representative must become a health care professional in order help to make sure the obtained information is precise and accurate but if Inadequate trained individuals takes the call there may work chances of misunderstandings.

\section{CASE PROCESSING}

The actual information is obtained from the reporter, the situation is entered onto a safety database, a story of the case is prepared and MedDRA term is assigned for the ADRs described each morning case. Inconsistencies in connection with case classification, serious/non-serious, labelled/unlabelled, arise the actual case processing. Case classification inconsistencies increase with the quantity of individuals responsible for processing cases; manual coding of MedDRA can also leads to several inconsistencies. Thus the totality out of all these inconsistencies during the situation handling process for giant volume PBRERs will likely have a considerable cause problem for the accuracy belonging to the PBRER and weaken the ability to recognize new signals or do a proper evaluation.

\section{DATA RETRIEVAL}

Specialists the most rate-limiting and time-consuming steps for high volume PBRERs, usually taking far over originally planned. To generate better accuracy and consistency, data retrieval can be performed by data managers or programmers rather compared to medical writers or reviewers. Also commercially ready databases can be employed for this project.

\section{ADR ANALYSIS}

Troubles faced in the ADR analysis are underreporting of ADRs, difficulty in calculating the exposure, and reporting the tendencies. In order to overcome these difficulties data mining methods pertaining to example Multi-Item Gamma Poison Shrinker (MGPS) method, Bayesian Confidence Propagation Neural Network (BCPNN), and Proportional Reporting Ratios (PRR), will automatically generate safety signals, from large ADR databases, without relying on incidences, and a most promising tool in signal sensors.

\section{MEDICAL REVIEW AND RISK ASSESSMENT}

Market strength of PBRER is the capability to review aggregate data which needs an all-inclusive look at many places such as summary tabulations and article on individual cases curiosity and also different sure whether the pattern of ADRs collected during the reporting interval has evolved. It is also essential to ensure whether any medically important events previously unlisted, but now emerged with a stronger causal relationship to the thing. Thus Medical review process needs a time to strengthen the PBRER which indirectly implies that if any 
of these processes, for instance if a process like data retrieval analysis is delayed it will seriously hamper the time for medical review and risk assessment and resulting within a poor quality PBRER. ${ }^{3,6}$

\section{COST AND RISK ASSESSMENT OF PSUR}

For a pharmaceutical company MAH to be able to spend around $€ 6000$ to acquire small PBRER $(<100$ ADR cases), $€ 14000$ for a medium PBRER (101-500 cases) and $€ 28000$ for an immense PSUR ( $>500$ cases). However spending this much money isn't a waste because PBRER is successful at signaling possibility and can prevent further adverse scores. There are 2 scenarios involving past year or so which PBRER played a massive role in preventing the adverse returns. One is by using Botulinum toxin type B which was approved in January 2001 and is indicated for your treatment of cervical dystonia. In March 2007 Direct Healthcare Professional Communication (DHPC) was issued, warning doctors about rare but serious side effects related on the peripheral spread of botulinum toxin. Within year 2002 rBMP (Bone Morphogenic Protein) was approved in therapy of tibial fractures and in February 2005 rBMP was approved for anterior lumbar spinal combination. In September 2007 DHPC was issued alerting physicians towards risk of complications occurred after unapproved use in posterior lumbar spinal synthesis.

The mainstream for quoting these incidents is to worry upon the cost of PBRER in risk assessment. Your market above mentioned cases the complications are going to have been identified even without PBRER nevertheless the issue of DHPC hold been delayed by around 5 seasons. Thus it is vital to continue PBRER to prevent the untoward risks of biological goods. ${ }^{9-11}$

\section{FUTURE CHALLENGES}

- $\quad$ Electronic PBRER format recently been proposed however the compliance of industry adhere to it in order to be affirmed

- $\quad$ Resource planning needs become clearly planned regarding the time, cost, training (in product, clinical, MedDRA training) and effective operations of PBRER.

- Growing involving newer immunomodulatory therapies also pose a strong challenge in identifying lengthy term risks.

- $\quad$ Risk management plan strategies needs turn out to be more precise and end up being served with regard to efficient tool in PBRER.

- Deadlines for submissions of PBRER its impact on your quality on the report end up being the greater responsibility among the MAH.

- Human factor management consists of SOPs, identifying the source of the human being errors and proper leadership and distance learning.

\section{CONCLUSION}

The field of Pharmacovigilance has crafted a tremendous journey since work out plans recognized the actual early 1960s after the thalidomide accident. Inevitably several new drugs like immunomodulators, anticancer medicine is on the raise which further adds a huge responsibility towards the regulatory agencies regarding the chance and advantages of such biological products Undoubtedly PBRERs plays an natural part and is relied on as an important tool involving field of pharmacovigilance but however the oversight is clearly to be able to ensure that this product's benefit continue to outweigh its risks, and PBRER facilitate the weighing and monitoring of such events at predetermined time points.

Funding: No funding sources

Conflict of interest: None declared

Ethical approval: Not required

\section{REFERENCES}

1. Verpilat P, Toumi M. Periodic Safety Update Reports. In: Mann RD, Andrews EB, editors. Pharmacovigilance. $2^{\text {nd }}$ Ed. West Sussex: John Wiley and Sons; 2009.

2. Guidance for Industry Providing Post Market Periodic Safety Reports in the ICH E2C (R2) Format (Periodic Benefit-Risk Evaluation Report). 2013 [accessed on 2016 Feb 9]. Available at: http://www.fda.gov/downloads/Drugs/GuidanceCom plianceRegulatoryInformation/Guidances/UCM3465 64.pdf

3. Module VII - Periodic safety update report. 2013 [accessed on 2016 Feb 2]. Available at: http://www.ema.europa.eu/docs/en_GB/document_li brary/Scientific_guideline/2013/04/WC500142468.p df

4. Submission of Periodic Safety Update Reports. 2012 [accessed on 2016 Feb 2]. Available at: http://www. www.cdsco.nic.in/writereaddata/Submission\%20of\% 20PSUR.pdf

5. E2C (R2) Implementation Working Group ICH E2C. 2014 [accessed 2016 Feb 2]. Available at: http://www.ich.org/fileadmin/Public_Web_Site/ICH_ Products/Guidelines/Efficacy/E2C/E2C_R2_QAs_St ep4.pdf

6. PBRER Draft Guideline - ICH. 2012 [accessed on 2016 Feb 1]. Available at: https://www.ich.org/fileadmin/Public_Web_Site/ICH _Products/Guidelines/Efficacy/E2C/E2C_R2_Step4.p df

7. Periodic benefit risk evaluation reports for medicinal products - Detailed guidance - GOV.UK. 2014 [accessed 2016 Feb 2]. Available at: https://www.gov.uk/guidance/periodic-benefit-riskevaluation-reports-for-medicinal-products

8. Ebbers HC, Mantel-Teeuwisse AK, SayedTabatabaei FA, Moors EHM, Schellekens H, Leufkens HGM. The role of Periodic Safety Update 
Reports in the safety management of biopharmaceuticals. Eur J Clin Pharmacol. 2013;69:217-26.

9. López MDC. Pharmacovigilance and risk management in the EU. Pharm Policy Law 2013;15:71-84.

10. Bouvy JC, Ebbers HC, Schellekens H, Koopmanschap MA. The cost-effectiveness of periodic safety update reports for biologicals in Europe. Clin Pharmacol Ther. 2013;93:433-42.

11. Jullian S, Jaskiewicz L, Pfannkuche HJ, Parker J, Lalande-Luesink I, Lewis DJ, et al. Aggregate analysis of regulatory authority assessors' comments to improve the quality of periodic safety update reports. Pharmacoepidemiol Drug Saf. 2015;24:97182.

Cite this article as: Krishnamurthy ACY, Dhanasekaran J, Natarajan A. A succinct medical safety: periodic safety update reports. Int J Basic Clin Pharmacol 2017;6:1545-51. 